\title{
REVIEW
}

\section{Noninvasive positive-pressure ventilation in acute respiratory failure}

\author{
Oscar Peñuelas MD, Fernando Frutos-Vivar MD, Andrés Esteban MD PhD
}

\section{ABSTRACT}

Noninvasive positive-pressure ventilation is a type of mechanical ventilation that does not require an artificial airway. Studies published in the 1990 s that evaluated the efficacy of this technique for the treatment of diseases as chronic obstructive pulmonary disease, congestive heart failure and acute respiratory failure have generalized its use in recent years. Important issues include the selection of the ventilation interface and the type of ventilator. Currently available interfaces include nasal, oronasal and facial masks, mouthpieces and helmets. Comparisons of the available interfaces have not shown one to be clearly superior. Both critical care ventilators and portable ventilators can be used for noninvasive positive-pressure ventilation; however, the choice of ventilator type depends on the patient's condition and therapeutic requirements and on the expertise of the attending staff and the location of care. The best results (decreased need for intubation and decreased mortality) have been reported among patients with exacerbations of chronic obstructive pulmonary disease and cardiogenic pulmonary edema.

Une version française de ce résumé est disponible à l'adresse www.cmaj.ca/cgi/content/full/I77/Io/I2II/DCI

CMAJ 2007;177(10):121I-8

$\mathrm{N}$ oninvasive positive-pressure ventilation is the delivery of mechanical ventilation to patients with respiratory failure without the requirement of an artificial airway. The key change that led to the recent increase in the use of this technique occurred in the early I980s with the introduction of the nasal continuous positive airway pressure mask for the treatment of obstructive sleep apnea. Studies published in the Iggos that evaluated the efficacy of noninvasive positive-pressure ventilation for treatment of diseases such as chronic obstructive pulmonary disease, congestive heart failure and acute respiratory failure have generalized its use in recent years. ${ }^{1}$ In 1998 , an international study on the use of mechanical ventilation found that $5 \%$ of patients admitted to intensive care units received noninvasive positive-pressure ventilation. ${ }^{2}$
Noninvasive positive-pressure ventilation includes various techniques for augmenting alveolar ventilation without an endotracheal airway. The clinical application of noninvasive ventilation by use of continuous positive airway pressure alone is referred to as "mask CPAP," and noninvasive ventilation by use of intermittent positive-pressure ventilation with or without continuous positive airway pressure is called noninvasive positive-pressure ventilation.

\section{Equipment and techniques for noninvasive ventilation}

\section{Interfaces}

The major difference between invasive and noninvasive ventilation is that with the latter technique gas is delivered to the airway via a mask or "interface" rather than an invasive tube. Interfaces are devices that connect the ventilator tubing to the patient's face and facilitate the entry of pressurized gas into the upper airway. The choice of interface is a crucial issue in noninvasive ventilation. Currently available interfaces include nasal, oronasal and facial masks, mouthpieces and helmets. Comparisons have not shown a clear superiority of one interface over the others. For treatment of acute respiratory failure, facial masks are most commonly used ( $70 \%$ of cases), followed by nasal masks $(25 \%)$ and nasal pillows $(5 \%){ }^{3}$

A full face mask is often a superior choice for patients with predominant mouth breathing because it reduces oral air leakage. The face mask permits mouth breathing, and it delivers higher ventilation pressures with less leakage and requires less patient cooperation than other interfaces. Compared with nasal masks, the more common use of full-face masks for the treatment of chronic respiratory failure is a reflection of better quality of ventilation (at least initially) in terms of improved minute ventilation and blood gases. ${ }^{4,5}$ However, face masks generally increase claustrophobia, impede communication, limit oral intake and expectoration of airway secretions and increases dead space, which may cause $\mathrm{CO}_{2}$ rebreathing.

From Intensive Care Service (Peñuelas, Frutos-Vivar, Esteban), Hospital Universitario de Getafe, Madrid, Spain; and Ciber de Enfermedades Respiratorias (Frutos-Vivar, Esteban), Instituto Carlos III, Spain. 
The helmet interface, which is a recent introduction, seems to possess important advantages over other interfaces. It is well tolerated by patients, allows acceptable interaction with the environment and can be used in difficult anatomic situations, such as for patients who are edentulous or have facial trauma. In contrast to facial masks, helmets do not make contact with the patient's face and therefore do not cause skin lesions. Helmets improve comfort, which permits longer periods of noninvasive positive-pressure ventilation delivery. However, because helmets are larger than facial masks, the pressure within the system during ventilation may be dissipated against the high compliance of the helmet, thus interfering with correct pressurization and ventilator function. ${ }^{6-8}$

\section{Ventilators and modes of ventilation}

Both critical care ventilators and portable ventilators can be used for noninvasive positive-pressure ventilation. The choice of ventilator type should depend on the patient's condition and on the expertise of the attending staff, the patient's therapeutic requirements and the location of care. ${ }^{3}$ The most common modes of non-invasive ventilation are continuous positive airway pressure and pressure support. An epidemiologic survey that included patients who received noninvasive positive-pressure ventilation for acute respiratory failure found that pressure support with or without positive end-expiratory pressure was used in $67 \%$ of cases and continuous positive airway pressure was used in $18 \% .{ }^{9}$

Although continuous positive airway pressure is not a true ventilation mode, it is often referred to as a form of noninvasive ventilation. This technique delivers constant positive pressure during both inspiration and expiration, either by use of a flow generator with a high pressure gas source or by use of a portable compressor. Continuous positive airway pressure can only be used if the patient is breathing spontaneously because it cannot support ventilation in the absence of a respiratory drive. The physiologic effects of continuous positive airway pressure include augmentation of cardiac output and oxygen delivery, improved functional residual capacity and respiratory mechanics, reduced effort for breathing and decreased left ventricular afterload. In patients with leftsided heart failure, continuous positive airway pressure improves the shunt fraction and reduces the inspiratory work of breathing. ${ }^{10}$ In chronic obstructive pulmonary disease, continuous positive airway pressure reduces the work of breathing by counterbalancing the inspiratory threshold load imposed by the intrinsic positive end-expiratory pressure created by airflow obstruction. ${ }^{11}$

Pressure support ventilation allows the patient to control inspiratory and expiratory times while providing a set pressure. In conjunction with patient effort and respiratory mechanics, the set pressure determines the inspiratory flow and tidal volume. The combination of inspiratory assistance with expiratory positive airway pressure (also known as bilevel ventilation or bilevel positive airway pressure) is thought to reduce the work of breathing and to alleviate respiratory distress more effectively than continuous positive airway pressure alone.

\section{Indications and effects}

\section{Exacerbations of chronic obstructive pulmonary disease}

Conventional management of exacerbations of chronic obstructive pulmonary disease includes bronchodilators, steroids, antibiotics and oxygen. Nonresponders and patients whose condition is severe may require ventilation support. Noninvasive positive-pressure ventilation is a well-evaluated intervention for these indications. An international consensus conference on noninvasive ventilation has recommended noninvasive positive-pressure ventilation as first-line treatment for exacerbations of chronic obstructive pulmonary disease that meet the criteria described in Box I. ${ }^{12}$ Box 2 presents the recommendations of the British Thoracic Society for treatment failure in noninvasive ventilation. ${ }^{13}$

Several studies and systematic reviews have assessed the efficacy of noninvasive positive-pressure ventilation for exacerbations of chronic obstructive pulmonary disease. ${ }^{14-16} \mathrm{~A}$ systematic review performed by Ram and colleagues ${ }^{15}$ included 8 studies. Compared with usual care alone, noninvasive positive-pressure ventilation was associated with lower mortality (relative risk [RR] 0.4I, 95\% confidence interval [CI] 0.26 to 0.64 ) (Figure I), decreased need for intubation (RR 0.42, 95\% CI 0.3I to 0.59), lower likelihood of treatment failure (RR 0.5I, 95\% CI 0.38 to 0.67 ) and, at I hour, greater improvements in $\mathrm{pH}$ (weighted mean difference $0.03,95 \%$ $\mathrm{CI} 0.02$ to 0.04 ), $\mathrm{PaCO}_{2}$ (weighted mean difference $-0.40 \mathrm{~mm}$ $\mathrm{Hg}, 95 \% \mathrm{CI}-0.78$ to -0.03 ) and respiratory rate (weighted mean difference -3.08 breaths per minute, 95\% CI -4.26 to - I.89). Noninvasive ventilation was associated with fewer treatment-related complications (RR 0.38, 95\% CI 0.24 to 0.60 ) and a shorter duration of hospital stay (weighted mean difference -3.24 days, $95 \% \mathrm{CI}-4.42$ to -2.06 ). Similar

Box 1: Recommendations from the International Consensus Conference in Intensive Care Medicine for the use of noninvasive positive-pressure ventilation in acute respiratory failure ${ }^{12}$

- Noninvasive positive-pressure ventilation can be initiated in the emergency department if staff have been adequately trained.

- Until more data are available, most patients who receive noninvasive positive-pressure ventilation should remain in an intensive care unit or in a system of care that is capable of providing high-level monitoring and where immediate access is available to staff skilled in invasive airway management.

- For selected patients with exacerbations of hypercapnic chronic obstructive pulmonary disease $(\mathrm{pH} \geq 7.30)$, noninvasive positive-pressure ventilation may be initiated and maintained in the ward if staff training and experience are adequate.

- If noninvasive positive-pressure ventilation is initiated outside the intensive care unit, failure to improve gas exchange, $\mathrm{pH}$, respiratory rate or dyspnea or the deterioration of either hemodynamic or mental status should prompt referral to the intensive care unit. 
conclusions were reported in subgroup analysis by Keenan and colleauges,${ }^{17}$ who found that these beneficial effects occurred only in cases with severe exacerbations and did not occur in cases with mild exacerbations.

Noninvasive positive-pressure ventilation has been compared with invasive mechanical ventilation in a randomized controlled trial ${ }^{18}$ that included 49 cases of chronic obstructive pulmonary disease with severe acute respiratory failure in which ventilatory support was deemed necessary. Respiratory failure was more severe in the cases enrolled in this study compared with previous studies. In addition, in previous trials noninvasive positive-pressure ventilation was used at an earlier stage (indicated by an average $\mathrm{pH}$ on study entry of 7.20). Within the noninvasive positive-pressure ventilation group, treatment failed in $12(52 \%)$ cases in which invasive mechanical ventilation was required. The authors found no significant differences between the treatment and control groups for mortality (intensive care unit or hospital), overall complications, duration of mechanical ventilation and length of stay in an intensive care unit. At I2-months follow-up, the rate of hospital re-admissions was lower in the noninvasive positive-pressure ventilation group than in the control group.

Additional evidence of the long-term benefits of noninvasive positive-pressure ventilation was presented by Confalonieri and colleagues. ${ }^{19}$ Among patients with chronic obstructive pulmonary disease exacerbations, patients who received noninvasive positive-pressure ventilation had increased survival at 6 months (treatment $7 \mathrm{I} \% \mathrm{v}$. control $5 \mathrm{I} \%, p<0.05$ ) and at $\mathrm{I}$ year (treatment $7 \mathrm{I} \%$ v. control $50 \%, p<0.05$ ).

Therefore, for selected patients with exacerbation of chronic obstructive pulmonary disease, the early use of noninvasive positive-pressure ventilation as a first-line therapy is associated with increased survival and decreased length of stay in hospital. Although the use of this therapy at advanced stages of acute respiratory failure is more likely to fail, a trial of noninvasive positive-pressure ventilation before proceeding to intubation and invasive ventilation does not seem to harm the patient and may be attempted cautiously. However, the patient should be closely monitored in an intensive care unit and, if required, intubation should be performed without excessive delay.

A schematic approach, initially proposed by Sinuff and colleauges,${ }^{20}$ for the use of noninvasive positive-pressure ventilation in cases with exacerbations of chronic obstructive pulmonary disease is shown in Figure 2. There is limited available information about the withdrawal of noninvasive positive-pressure ventilation; thus, the strategy proposed by Sinuff and colleauges ${ }^{21}$ may be helpful in cases of chronic obstructive pulmonary disease (Figure 3).

\section{Asthma}

The low incidence of acute respiratory failure secondary to status asthmaticus ${ }^{2}$ may be the reason why few studies have evaluated the efficacy of noninvasive positive-pressure ventilation in this setting. In a prospective study involving I7 patients with status asthmaticus, Meduri and colleagues ${ }^{22}$ reported that noninvasive positive-pressure ventilation (by use of a face mask) with a low inspiratory pressure is highly effective in correcting gas exchange abnormalities. Of the I7 included patients, 2 ( $12 \%$ ) required intubation and none developed complications. In a retrospective study involving 33 patients who had been admitted to an intensive care unit for status asthmaticus, Fernández and colleagues ${ }^{23}$ reported that II patients received invasive mechanical ventilation and 22 patients received noninvasive positive-pressure ventilation. They found no differences in the median length of stay in an intensive care unit (4.5 days v. 3 days) or hos-

Box 2: Recommendations of the British Thoracic Society Standards of Care Committee for treatment failure in noninvasive ventilation ${ }^{13}$

Is treatment of the underlying condition optimal?

- Check what medical treatment has been prescribed and that it has been given

- Consider physiotherapy for sputum retention

Have any complications developed?

- Consider pneumothorax or aspiration pneumonia

If $\mathrm{PaCO}_{2}$ remains elevated:

- Is the patient receiving too much oxygen? - adjust $\mathrm{FiO}_{2}$ to maintain $\mathrm{SpO}_{2}$ between $85 \%-90 \%$

- Is there excessive leakage?

- check mask fit

- if using a nasal mask, consider a chin strap or a fullface mask

- Is the circuit set up correctly?

- check that connections have been made correctly

- check the circuit for leaks

- Is rebreathing occurring?

- check potency of expiratory valve (if fitted)

- consider increasing expiratory positive airway pressure (if receiving bilevel pressure support)

- Is the patient's breathing synchronized with the ventilator?

- observe patient

- adjust rate or inspiration-expiration ratio (with assist/control mode)

- check inspiratory trigger (if adjustable)

- check expiratory trigger (if adjustable)

- consider increasing expiratory positive airway pressure (with bilevel pressure support in chronic obstructive pulmonary disease)

- Is ventilation inadequate?

- observe chest expansion

- increase target pressure or volume

- consider increasing inspiratory time

- consider increasing respiratory rate (to increase minute ventilation)

- consider a different mode of ventilation or ventilator, if available

If $\mathrm{PaCO}_{2}$ improves but $\mathrm{PaO}_{2}$ remains low:

- Increase $\mathrm{FiO}_{2}$

- Consider increasing expiratory positive airway pressure (with bilevel pressure support) 
pital (I5 days v. I2 days). They also found no difference in mortality (0\% v. $4 \%$ ).

A recent systematic review identified only I randomized controlled trial of noninvasive positive-pressure ventilation in patients with status asthmaticus. ${ }^{24,25}$ In this study, which included 30 patients, noninvasive positive-pressure ventilation significantly improved lung function test results. ${ }^{25}$ In the noninvasive positive-pressure ventilation group, $80 \%$ of patients reached the predetermined primary end points (an increase of at least $50 \%$ in $\mathrm{FEV}_{1}$ compared with baseline), yet only $20 \%$ of patients in the control group reached the end points $(p<0.004)$. The mean rise in $\mathrm{FEV}_{1}$ was $53.5 \%$ (standard deviation [SD] 23.4\%) in the noninvasive positivepressure ventilation group and $28.5 \%$ (SD 22.6\%) in the conventional treatment group $(p=0.006)$. In an intention-totreat analysis, admission to hospital was required for 3 of 17 patients $(\mathrm{I} 7.6 \%)$ in the noninvasive positive-pressure ventilation group and for Io of $\mathrm{I} 6$ patients $(62.5 \%)$ in the control group $(p=0.0134) .{ }^{25}$

The application of noninvasive positive-pressure ventilation in patients suffering from status asthmaticus remains controversial, despite some interesting and very promising preliminary results. Large randomized controlled trials are needed to determine the role of noninvasive positive-pressure ventilation in status asthmaticus.

\section{Acute cardiogenic pulmonary edema}

The best specific respiratory support for treatment of acute respiratory failure due to cardiogenic pulmonary edema remains unclear. In its guidelines for the diagnosis and treatment of acute heart failure, the European Society of Cardiology recommend the use of noninvasive positive-pressure ventilation (recommendation: class IIA, level of evidence: A). ${ }^{26}$ Three randomized controlled trials have suggested that the use of noninvasive intermittent positive-pressure ventilation in the setting of acute cardiogenic pulmonary edema $^{27-29}$ decreases the need for intubation; however, this does not translate into reduced mortality or improved longterm function.

In a recent meta-analysis ${ }^{30}$ that included a total of 29 randomized controlled trials of continuous positive airway pressure and bilevel positive airway pressure, Peter and colleauges reported on I2 studies that compared continuous positive airway pressure with standard care, 7 that compared bilevel positive airway pressure with standard care and io that compared continuous positive airway pressure with bilevel positive airway pressure. Continuous positive airway pressure was associated with a significant reduction in hospital mortality compared with standard therapy (RR $0.59,95 \% \mathrm{CI} 0.38$ to $0.90, p=0.015$ ). However, the effect of bilevel positive airway pressure was not significant (RR 0.63 , $95 \% \mathrm{CI} 0.37$ to I.IO, $p=0.1 \mathrm{I})$. Both continuous positive airway pressure and bilevel positive airway pressure were associated with significant reductions in the need for invasive mechanical ventilation compared with standard therapy (continuous positive airway pressure v. standard therapy RR $0.44,95 \% \mathrm{CI} 0.29$ to $0.66, p=0.0003$; bilevel positive airway pressure v. standard therapy RR $0.50,95 \% \mathrm{CI} 0.27$ to $0.90, p=0.02$ ). Compared with standard therapy, neither continuous positive airway pressure nor bilevel positive airway pressure had an effect on new myocardial infarction rates or length of hospital stay.

\section{Uses in other causes of acute respiratory failure}

Noninvasive positive-pressure ventilation has been used in patients with acute respiratory failure that occurred postsurgery or that occurred because of community-acquired pneumonia. A systematic review by Keenan and colleagues ${ }^{31}$ analyzed the efficacy of this technique in patients with hypoxemic respiratory failure. They reported on the outcome of 2 trials that included immunocompromised patients, I that included patients who had undergone lung resection, I that included patients with community-acquired pneumonia, I that included patients with post-extubation respiratory failure and 3 that included a heterogeneous groups of patients. Overall, noninvasive positivepressure ventilation was associated with a significantly lower rate of intubation compared with standard management (absolute risk reduction $23 \%$, $95 \% \mathrm{CI}$ 10\% to $35 \%$ ). The results were similar for the subgroup of 6 trials that did not include patients with chronic obstructive pulmonary disease or cardiogenic pulmonary edema (risk reduction $24 \%, 95 \%$ CI $8 \%$ to $36 \%$. Also, noninvasive positivepressure ventilation was associated with a reduction in mortality in intensive care units of $17 \%$ ( $95 \%$ CI $8 \%$ to $26 \%$ ), with the same subgroup of 6 trials reporting a similar reduction of $\mathrm{I} 6 \%$ ( $95 \% \mathrm{CI} 5 \%$ to $27 \%$ ).

Following publication of the metaanalysis by Keenan and colleauges, ${ }^{31} 2$ additional studies have been performed. ${ }^{32,33}$ Squadrone and colleagues ${ }^{32}$ examined the effectiveness of continuous positive airway pressure in patients with acute hypoxemia after elective major abdominal surgery. Patients who received oxygen and continu- 
ous positive airway pressure had a lower intubation rate (RR 0.099, 95\% CI o.oI to 0.76 ) and none of these patients died in hospital, compared with 3 deaths among the group of patients who received oxygen alone $(p=0.12) .^{32}$ The study by Honrubia and colleagues ${ }^{33}$ included 64 patients with acute respiratory failure from various causes. These patients were randomized to receive either noninvasive positive-pressure ventilation through a face mask with pressure support and positive end-expiratory pressure or to receive conventional invasive ventilation. Noninvasive ventilation reduced the need for intubation (relative risk reduction $43 \%$ ). Mortality in intensive care units was $23 \%$ in the noninvasive group and $39 \%$ in the conventional therapy group $(p=0.09)$.

The heterogeneity among studies suggests that the effectiveness of noninvasive positive-pressure ventilation varies among different populations and does not support its routine use in all patients with acute hypoxemic respiratory failure. In fact, the conclusion of the International Consensus Conference in Intensive Care Medicine is that larger controlled studies are required to determine the potential benefit of using this type of ventilation in addition to standard medical treatment in the avoidance of endotracheal intubation in hypoxemic acute respiratory failure..$^{34}$

\section{Noninvasive ventilation as a mode of weaning from mechanical ventilation}

Interest has emerged in the use of noninvasive positive-pressure ventilation as a mode of ventilation weaning. Recently, several studies have assessed the role of this type of ventilation in facilitating earlier extubation. ${ }^{35-37}$ Burns and colleagues $^{38}$ performed a meta-analysis of 5 studies that included a total of $17 \mathrm{I}$ patients. They found that, compared with weaning strategies that involved invasive mechanical ventilation alone, noninvasive positive-pressure ventilation decreased mortality (RR 0.4I, 95\% CI 0.22 to 0.76 ), incidence of ventilatorassociated pneumonia (RR $0.28,95 \%$ $\mathrm{CI} 0.09$ to 0.85 ), length of stay in an intensive care unit (weighted mean difference -6.88 days, $95 \% \mathrm{CI}-\mathrm{I} 2.60$ to - I.I5), length of stay in hospital (weighted

If the patient does not respond to standard medical therapy, consider a trial of noninvasive positive-pressure ventilation

\section{Eligibility Criteria}

Clinical (all must be met)

- Exacerbation of congestive heart failure

or chronic obstructive pulmonary disease

- $>18 \mathrm{yr}$

- Able to protect airway

- Able to clear airway secretions

- Respiratory rate > $30 \mathrm{bpm}$

Gas exchange (all should be met)

- $\mathrm{pH}<7.35$

- $\mathrm{PaCO}_{2}>50 \mathrm{~mm} \mathrm{Hg}$

- $\mathrm{PaO}_{2}<60 \mathrm{~mm} \mathrm{Hg}$ on $\mathrm{FiO}_{2} 0.21$

or $\mathrm{PaO}_{2} / \mathrm{FiO}_{2}<200$

Radiographic (must be met)

- No pneumothorax

\section{Contraindications}

- Cardiac arrest or dysrhythmias

- Acute coronary syndrome

- Hemodynamic instability (systolic blood pressure $<90 \mathrm{~mm} \mathrm{Hg}$ )

- Immediate endotracheal intubation necessary

- Apnea

- Upper airway obstruction

- Decreased level of consciousness (moderately severe to severe)

- Upper gastrointestinal bleeding

- Facial trauma

- Vomiting

- Pregnancy

- Patient declines

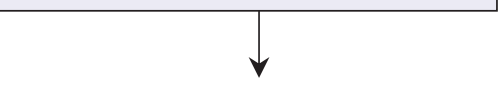

Physician assessment Nursing assessment

- Clinical assessment - Clinical assessment

- Chest radiograph - Acclimatize patient

- Arterial blood gases 1:1 nursing

- Electocardiogram - Patient stability

Continue optimizing medical therapy

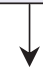

Initial order for and initiation of noninvasive positive-pressure ventilation

- Continuous positive-pressure ventilation for congestive heart failure

- Bilevel positive airway pressure or pressure support for chronic obstructive pulmonary disease

- Pulmonary consultation for noninvasive positive-pressure ventilation parameters and follow-up

- Full face mask

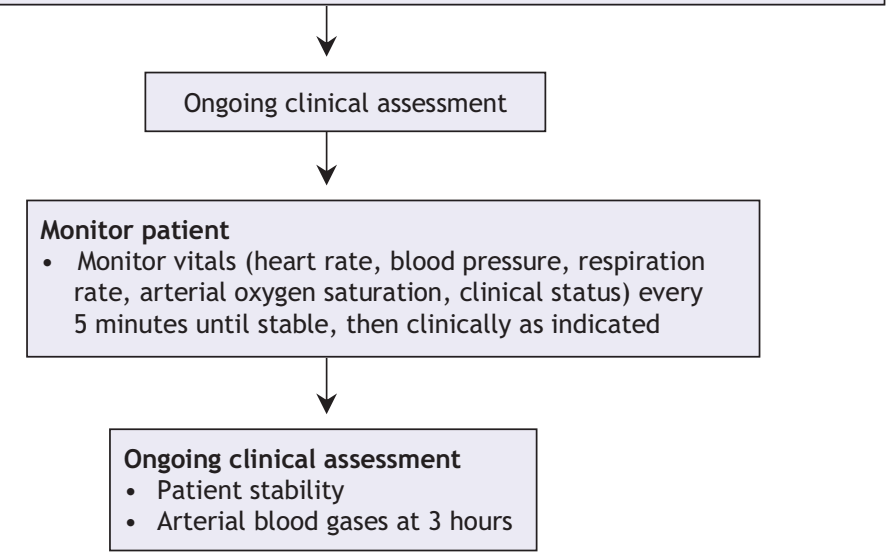

Figure 2: Practice guideline for the use of noninvasive positive-pressure ventilation for treatment of acute respiratory failure in patients with chronic obstructive pulmonary disease and congestive heart failure. Modified with permission from The American College of Chest Physicians (Chest 2003;123:2062-73). ${ }^{20}$ 
mean difference -7.33 days, $95 \% \mathrm{CI}-\mathrm{I} 4.05$ to $-0.6 \mathrm{I})$, total duration of mechanical support (weighted mean difference -7.33 days, $95 \% \mathrm{CI}-\mathrm{II} .45$ to -3.22 ) and the duration of invasive mechanical ventilation (weighted mean difference -6.79 days, $95 \%$ CI - II.70 to - I. 87 ). In a subgroup analyses, they found that the mortality benefit of noninvasive positive-pressure ventilation was greatest among patients with chronic obstructive pulmonary disease; however, bias and methodologic flaws in some of the included studies could limit the generalizability of this conclusion. ${ }^{39}$

\section{Noninvasive ventilation for prevention of respiratory failure}

In recent years, useful guidelines for weaning from mechanical ventilation have developed; however, the rate of extubation failure (the need for reintubation within $48-72$ hours) is close to $18 \%{ }^{40}$ The main cause of extubation failure is the development of respiratory failure within a few hours. Noninvasive positive-pressure ventilation has been evaluated in the prevention and management of this condition. Until recently, experience with noninvasive positive-pressure ventilation was limited to observational studies with physiologic evaluation as the main objective.

In a randomized controlled trial that included 93 patients, Jiang and colleagues ${ }^{41}$ reported on the outcomes of 56 patients who received elective extubation and 37 patients who received unplanned extubation. After extubation, patients were randomly assigned to receive either bilevel positive airway pressure or unassisted oxygen therapy. They found no significant difference in the rate of reintubation for either technique (noninvasive positive-pressure ventilation $28 \% \mathrm{v}$. oxygen therapy $15 \%$ ).
Nava and colleagues ${ }^{42}$ performed a randomized controlled trial that included 97 consecutive patients who required more than 48 hours of mechanical ventilation and who were considered at risk for post-extubation respiratory failure. After a successful weaning trial, patients were randomized to receive either noninvasive positive-pressure ventilation or standard medical therapy. Compared with standard therapy, there was a lower rate of reintubation among those in the noninvasive positive-pressure ventilation group (RR $0.34,95 \%$ CI 0.12 to 0.98 ). Noninvasive positivepressure ventilation did not affect overall mortality in the intention-to-treat analysis, but the authors reported reduced mortality in the intensive care unit setting owing to a reduced need for reintubation.

In 2006, Ferrer and colleauges ${ }^{43}$ conducted a randomized controlled trial that included $\mathrm{I}_{2}$ patients receiving mechanical ventilation who tolerated a spontaneous breathing trial but who were at increased risk for respiratory failure after extubation. After extubabtion, patients were randomly allocated to receive 24 hours of either noninvasive positive-pressure ventilation or conventional management with oxygen therapy. Among patients who received noninvasive positivepressure ventilation, respiratory failure after extubation was less frequent (RR 0.5I, 95\% CI 0.28 to 0.9I), but 90-day mortality was not reduced. Subgroup analysis showed that the use of noninvasive positive-pressure ventilation was associated with reduced mortality among patients with hypercapnia.

Based on these studies, the early use of noninvasive positive-pressure ventilation can prevent respiratory failure after extubation and decrease the need for reintubation. However, further studies that better define the population of patients at risk for respiratory failure after extubation may be necessary.

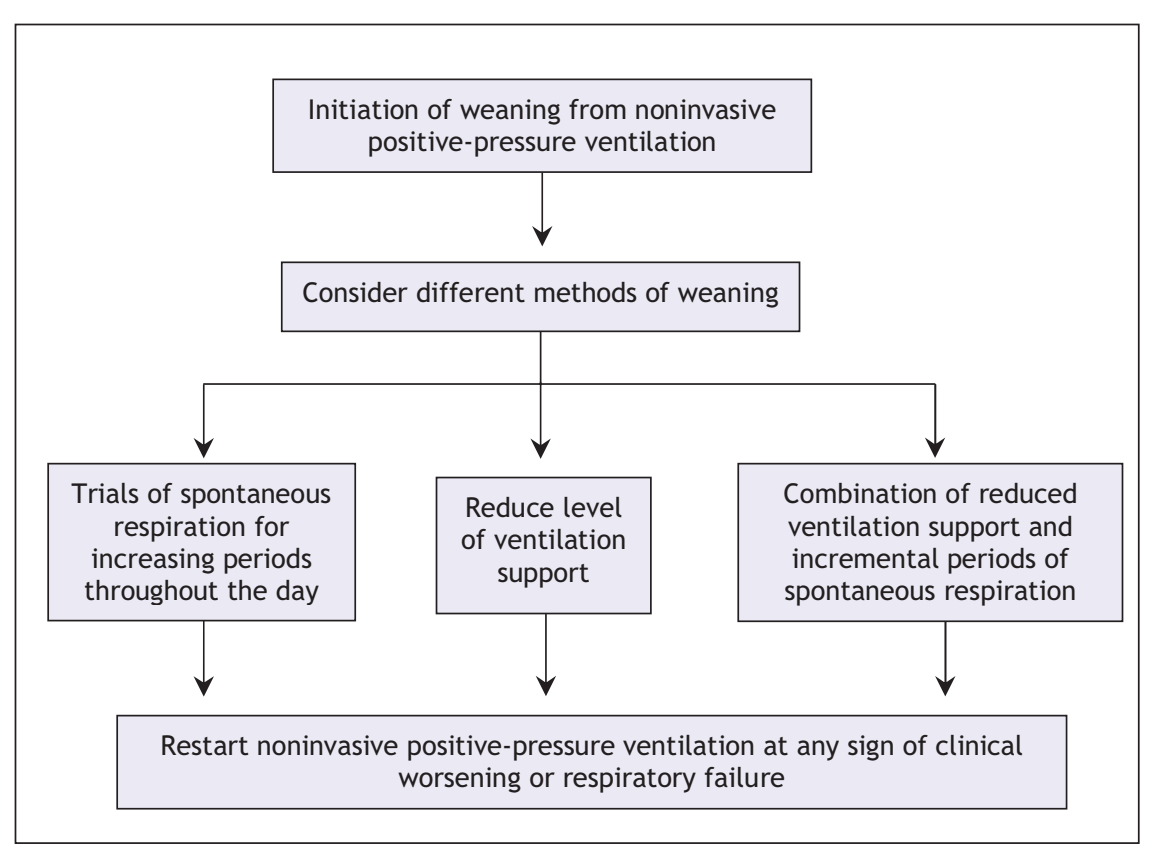

Figure 3: Algorithm for weaning from noninvasive positive-pressure ventilation for patients with acute respiratory failure due to exacerbations of chronic obstructive pulmonary disease. Modified with permission from Elsevier (J Crit Care 2004;19:82-91). ${ }^{21}$

\section{Noninvasive ventilation for management of respiratory failure}

The treatment of respiratory failure after extubation must be considered separately. Two randomized controlled trials that examined the effectiveness of noninvasive positive-pressure ventilation in this context have been published. Keenan and colleagues $^{44}$ enrolled 8I patients who required ventilatory support for more than 2 days and who developed respiratory distress within 48 hours of extubation. Patients were randomly assigned to receive standard medical therapy alone or to receive noninvasive positive-pressure ventilation by use of a face mask and standard medical therapy. The authors found no difference in the rate of reintubation (RR I.04, 95\% CI 0.78 to I.38) or hospital mortality (RR 0.99, 95\% CI 0.52 to I.9I).

Using similar methodology, Esteban and colleagues ${ }^{45}$ performed a multicentre international study that included 22I patients. In this study, there was no difference in the need for reintubation 
among patients receiving noninvasive positive-pressure ventilation and those receiving standard therapy (RR 0.99, $95 \%$ CI 0.76 to I.30). However, mortality in the intensive care unit was higher in the noninvasive positive-pressure ventilation group compared with the standard-therapy group (RR I.78, 95\% CI I.03 to 3.20). A possible explanation for this difference is delayed reintubation among patients who received noninvasive positive-pressure ventilation. The median time from respiratory failure to reintubation was longer in the noninvasive positivepressure ventilation group compared with standard care (I2 h v. 2 h $30 \mathrm{~min}$ ).

In light of these studies, noninvasive positive-pressure ventilation is not effective for management of post-extubation respiratory failure, and delayed reintubation may increase mortality.

\section{Noninvasive ventilation in patients with a "do-not- intubate" order}

Noninvasive positive-pressure ventilation has been used as an alternative to invasive ventilation in patients with a "donot-intubate" order. A recent study ${ }^{46}$ that included II4 patients with a do-not-intubate order and acute respiratory failure found that $43 \%$ of patients survived to hospital discharge. The patient's underlying condition was an important determinant of survival. Mortality was $25 \%$ among patients with chronic heart failure and $48 \%$ among patients with chronic obstructive pulmonary disease. Mortality was highest among patients with cancer and pneumonia $(77 \%$ and $74 \%$ respectively).

Similar results were reported by Schettino and colleagues ${ }^{47}$ in a prospective observational study that included I3I patients with acute respiratory failure and a do-not-intubate order in a general hospital. They reported an overall mortality of $64.9 \%$. Hospital mortality was $37.5 \%$ among patients with chronic obstructive pulmonary disease exacerbations, 39\% among those with cardiogenic pulmonary edema, $68 \%$ among those with nonchronic obstructive pulmonary disease hypercapnic respiratory failure, $77 \%$ among those with post-extubation respiratory failure and $88 \%$ among patients with hypoxemic acute respiratory failure. Advanced cancer was present in 40 patients, and it was associated with increased risk of death (mortality $85 \%$, odds ratio [OR] $4.44,95 \%$ CI I.70 to Ir.62, $p=0.002)$.

\section{Contraindications}

Although noninvasive ventilation is very useful in many settings, it is not appropriate for all patients. There are a number of absolute and relative contraindications for this mode of ventilation (Box 3).

Noninvasive ventilation for respiratory support requires that patients are cooperative and able to protect their airway. Therefore, substantially impaired consciousness or an inability to protect the upper airway should lead physicians to choose another type of respiratory support.

It is also unsafe to use facial masks for patients who are vomiting repeatedly or who are bleeding from the airways or the upper gastrointestinal tract. Vomiting or bleeding into the facial mask will invariably predispose the patient to aspiration. Considerable airway secretions pose a similar problem.

One of the potential complications of noninvasive positive-pressure ventilation is abdominal distention due to the air forced into the stomach under positive pressure. If a patient has anastomoses in the upper gastrointestinal tract, physicians should avoid the possibility of disrupted suture lines because of abdominal distention.

Finally, noninvasive positive-pressure ventilation has not been shown to benefit patients with acute coronary syndromes. The combination of acute myocardial ischemia with hypoxemic respiratory failure and possibly hemodynamic instability may result in worsened myocardial ischemia compared to invasive modalities for which one would expect more immediate control of oxygenation and hemodynamic status.

\section{Conclusion}

Noninvasive positive-pressure ventilation is effective for reversing acute respiratory failure and preventing hospital mortality in patients with a do-not-intubate order whose primary diagnosis is chronic obstructive pulmonary disease or cardiogenic pulmonary edema. It is a less successful therapy for patients with hypoxemic acute respiratory failure or terminal cancer. Robust evidence from randomized controlled trials is lacking.

Box 3: Contraindications for the use of noninvasive positive-pressure ventilation

Absolute

- Substantially impaired level of consciousness

- Severe agitation

- Copious secretions

- Uncontrolled vomiting

- Inability to protect airway

- Repeated hemoptysis or hematemesis

- Recent esophagectomy

- Acute myocardial infarct

- Cardiac arrest

- Immediate endotracheal intubation necessary

- Apnea

- Upper airway obstruction

- Facial trauma

- Patient declines

Relative

- Mildly decreased level of consciousness

- Progressive severe respiratory failure

- Uncooperative patient who can be calmed or comforted

- Suspected acute coronary ischemia

- Hemodynamic instability

- Pregnancy 
This article has been peer reviewed.

Competing interests: None declared.

Contributors: All of the authors contributed to the conception and design of the article and to the interpretation of the data. All of the authors drafted the article and revised it for important intellectual content and gave approval of the version to be published.

\section{REFERENCES}

I. Mehta S, Hill NS. Noninvasive ventilation. Am J Respir Crit Care Med 2001;163: 540-77.

2. Esteban A, Anzueto A, Frutos-Vivar F, et al. Characteristics and outcomes in adult patients receiving mechanical ventilation: a 28 -day internacional study. JAMA 2002;287:345-55

3. Schonhofer B, Sortor-Leger S. Equipment needs for noninvasive mechanical ventilation. Eur Respir J 2002;20:1029-36.

4. Meduri GU, Turner RE, Abou-Shala N, et al. Noninvasive positive-pressure ventilation via face mask. First-line intervention in patients with acute hypercapnic and hypoxemic respiratory failure. Chest 1996 ; Io9:179-93.

5. Navalesi P, Fanfulla F, Frigerio P, et al. Physiologic evaluation of noninvasive mechanical ventilation delivered with three types of masks in patients with chronic hypercapnic respiratory failure. Crit Care Med 2000;28:1785-90.

6. Chiumello D, Pelosi P, Carlesso E, et al. Noninvasive positive-pressure ventilation delivered by helmet vs. standard face mask. Intensive Care Med 2003;29:I67I-9.

7. Costa R, Navalesi P, Antonelli M, et al. Physiologic evaluation of different levels of assistance during noninvasive ventilation delivered through a helmet. Chest 2005;128:2984-90.

8. Navelesi P, Costa R, Ceriana P, et al. Noninvasive ventilation in chronic obstructive pulmonary disease patients: helmet versus facial mask. Intensive Care Med 2007;33:74-8I.

9. Carlucci A, Richard JC, Wysocki M, et al. Noninvasive versus conventional mechanical ventilation. An epidemiologic survey. Am J Respir Crit Care Med 200I; I63:874-8o.

Io. Lin M, Yang YF, Chiang HT, et al. Reappraisal of continuous positive airway pressure therapy in acute cardiogenic pulmonary edema. Short-term results and longterm follow-up. Chest I995;107:1379-86.

II. Petrof BJ, Legare M, Goldberg P, et al. Continuous positive airway pressure reduces work of breathing and dyspnea during weaning from mechanical ventilation in severe chronic obstructive pulmonary disease. Am Rev Respir Dis I990;I4I:28I-90.

I2. Evans TW. International Consensus Conferences in Intensive Care Medicine. Noninvasive positive-pressure ventilation in acute respiratory failure. Intensive Care Med 200I;27:I66-78.

I3. British Thoracic Society Standards of Care Committee. Noninvasive ventilation in acute respiratory failure. Thorax 2002;57:192-2II.

I4. Peter JV, Moran JL, Phillips-Hughes J, et al. Noninvasive ventilation in acute respiratory failure - a meta-analysis update. Crit Care Med 2002;30:555-62.

I5. Ram FS, Picot J, Lightowler J, et al. Noninvasive positive-pressure ventilation for treatment of respiratory failure due to exacerbations of chronic obstructive pulmonary disease. Cochrane Database Syst Rev 2004; (3):CDoo4I04.

I6. Collaborative Research Group of Noninvasive Ventilation for Chronic Obstructive Pulmonary Disease. Early use of noninvasive positive-pressure ventilation for acute exacerbations of chronic obstructive pulmonary disease: a multicenter randomized controlled trial. Chin Med J (Engl) 2005;II8:2034-40.

17. Keenan SP, Sinuff T, Cook DJ, et al. Which patients with acute exacerbations of chronic obstructive pulmonary disease benefit from noninvasive positive-pressure ventilation? A systematic review of the literature. Ann Intern Med 2003;13 8:86I-70.

I8. Conti G, Antonelli M, Navalesi P, et al. Noninvasive versus conventional mechanical ventilation in patients with chronic obstructive pulmonary disease after failure of medical treatment in the ward: a randomized trial. Intensive Care Med 2002;28:170I-7.

I9. Confalonieri M., Parigi P, Scartabellati A, et al. Noninvasive mechanical ventilation improves the immediate and long-term outcome of COPD patients with acute respiratory failure. Eur Respir J I996;9:422-30.

20. Sinuff T, Cook DJ, Randall J, et al. Evaluation of a practice guideline for noninvasive positive-pressure ventilation for acute respiratory failure. Chest 2003;123:2062-73.

2I. Sinuff T, Keenan S. Clinical practice guideline for the use of noninvasive positivepressure ventilation in COPD patients with acute respiratory failure. J Crit Care 2004;19:82-9I.
22. Meduri GU, Cook TR, Turner RE, et al. Noninvasive positive-pressure ventilation in status asthmaticus. Chest 1996;110:767-74.

23. Fernández MM, Villagra A, Blanch L, et al. Noninvasive mechanical ventilation in status asthmaticus. Intensive Care Med 2001;27:486-92.

24. Ram FS, Wellington S, Rowe B, et al. Noninvasive positive-pressure ventilation for treatment of respiratory failure due to severe acute exacerbations of asthma. Cochrane Database Syst Rev 2005; (3):CDoo4360.

25. Soroksky A, Satv D, Shpirer I. A pilot prospective, randomized, placebo-controlled trial of bilevel positive airway pressure in acute asthmatic attack. Chest 2003;123:I018-25.

26. Nieminen MS, Bohm M, Cowie MR, et al. Executive summary of the guidelines on the diagnosis and treatment of acute heart failure. Eur Heart J 2005;26:384-4I6.

27. Masip J, Betbesé AJ, Páez J. Noninvasive pressure-support ventilation versus conventional oxygen therapy in acute cardiogenic pulmonary oedema a randomized trial. Lancet 2000;356:2126-32.

28. Sharon A, Shpirer I, Kaluski E, et al. High-dose intravenous isosorbide-dinitrate is safer and better than BiPAP ventilation combined with conventional treatment for severe pulmonary edema. JAm Coll Cardiol 2000;36:832-7.

29. Mehta S, Jay GD, Woolard RH, et al. Randomized prospective trial of bilevel versus continuous positive airway pressure in acute pulmonary edema. Crit Care Med I997;25:620-8.

30. Peter JV, Moran JL, Hughes JP, et al. Effect of noninvasive positive-pressure ventilation (NIPPV) on mortality in patients with acute cardiogenic pulmonary oedema: a meta-analysis. Lancet 2006;367:1155-63.

3I. Keenan S, Sinuff T, Cook D, et al. Does noninvasive positive-pressure ventilation improve outcome in acute hypoxemic respiratory failure? A systematic review. Crit Care Med 2004;32:2516-23.

32. Squadrone V, Coha M, Cerutti E, et al. Continuous positive airway pressure for treatment of postoperative hypoxemia: a randomized controlled trial. JAMA 2005;293:589-95.

33. Honrubia T, García López FJ, Franco N, et al. Noninvasive vs conventional mechanical ventilation in acute respiratory failure: a multicenter, randomized controlled trial. Chest 2005;128:3916-24.

34. International Consensus Conference in Intensive Care Medicine: non-invasive positive-pressure ventilation in acute respiratory failure. Am J Respir Crit Care Med 200I;163:283-9I.

35. Nava S, Ambrosino N, Clini E. Noninvasive mechanical ventilation in the weaning of patients with respiratory failure due to chronic obstructive pulmonare disease. A randomized controlled trial. Ann Intern Med I998;I28:72I-8.

36. Girault C, Daudenthun I, Chevron V, et al. Noninvasive ventilation as a systematic extubation and weaning technique in acute-on-chronic respiratory failure: a prospective, randomized controlled study. Am J Respir Crit Care Med 1999;160:86-92.

37. Ferrer M, Esquinas A, Arancibia F, et al. Noninvasive ventilation during persistent weaning failure: a randomized controlled trial. Am J Respir Crit Care Med 2003;168:70-6.

38. Burns KE, Adhikari NK, Meade MO. Noninvasive positive-pressure ventilation as a weaning strategy for intubated adults with respiratory failure. Cochrane Database Syst Rev 2003;(4):CDoo4I27.

39. Benito S. Ventilación no invasiva en el fracaso del weaning. Med Intensiva 2004;28: I8-9.

40. Gil B, Frutos-Vivar F, Esteban A. Deleterious effects of reintubation of mechanically ventilated patients. Clinical Pulmonary Medicine 2003;10:226-30.

4I. Jiang JS, Kao SJ, Wang SN. Effect of early application of biphasic positive airway pressure on the outcome of extubation in ventilator weaning. Respirology I999;4:I6I-5.

42. Nava S, Gregoretti C, Farfulla F, et al. Noninvasive ventilation to prevent respiratory failure after extubation in high-risk patients. Crit Care Med 2005;33:2465-70.

43. Ferrer M, Valencia M, Nicolás JM, et al. Early noninvasive ventilation averts extubation failure in patients at risk. Am J Respir Crit Care Med 2006;173:164-70.

44. Keenan SP, Powers C, McCormack DG, et al. Noninvasive positive -ressure ventilation for postextubation respiratory distress: a randomized controlled trail. JAMA 2002:287;3238-44

45. Esteban A, Frutos-Vivar F, Ferguson ND, et al. Noninvasive positive-pressure ventilation for respiratory failure after extubation. N Engl J Med 2004;350:2452-60.

46. Levy M, Tanios MA, Nelson D, et al. Outcomes of patients with do-not-intubate orders treated with noninvasive ventilation. Crit Care Med 2004;32:2002-7.

47. Schettino G, Altobelli N, Kacmarek RM. Noninvasive ventilation reverses acute respiratory failure in selected "do-not-intubate" patients. Crit Care Med 2005;33:1976-82.

Correspondence to: Dr. Andrés Esteban, Intensive Care Unit, Hospital Universitario de Getafe, 28905 Madrid, Spain; fax 34-9I6832095; aesteban@ucigetafe.com 